malignant hyperthermia, may offer an effective treatment. ${ }^{56}$

\footnotetext{
References

${ }^{1}$ Delay J, Pichot P, Lemperiere T, Elissalde B, Perigre F. Un neuroleptique majeur non phenothiazin que et non reserpinque l'haloperidol dans le traitment dès psychoses. Ann Med Psychol (Paris) 1960;118:145-52.

2 Caroff SN. The neuroleptic malignant syndrome. J Clin Psychiatry 1980;41:79-83.

${ }^{3}$ Smego RA, Duralk DT. The neuroleptic malignant syndrome. Arch Intern Med 1982;142:1183-5.
}

${ }^{4}$ Cohen WJ, Cohen NH. Lithium carbonate, haloperidol and irreversible brain damage. JAMA 1974;230:1283-7.

${ }^{5}$ Coons DJ, Hillman FJ, Marshall RW. Treatment of neuroleptic malignant syndrome with dantrolene sodium. A case report. Am J Psychiatry 1982:139:944-5.

${ }^{6}$ Goulon M, De Rohan Chabot P, Elkharrat D, et al. Beneficial effects of dantrolene in the treatment of neuroleptic malignant syndrome. A report of two cases. Neurology (NY) 1983;33: 516-8.

Correspondence to Dr H Monaghan, Our Lady's Hospital for Sick Children, Crumlin, Dublin 12, Ireland.

Received 24 March 1986

\title{
Oral administration of active vitamin D metabolites to low birthweight infants
}

\author{
I Z KOVAR, P D MAYNE, J J JAMES, AND I C BARNES \\ Departments of Child Health and Chemical Pathology, Charing Cross and Westminster Medical School, \\ London
}

SUMmarY The active vitamin D metabolites $1 \alpha, 25-$ dihydroxycholecalciferol (Rocaltrol) and the analogue $1 \alpha$-hydroxycholecalciferol (One-Alpha) are adequately absorbed after oral administration in the preterm infant. The absorption pattern is similar to that seen in adults.

Bone demineralisation is common in low birthweight preterm infants, with a reported incidence of up to $32 \%$. Vitamin D metabolites are prescribed in the management and prophylaxis of early onset hypocalcaemia and rickets. ${ }^{12}$ There is little information available on the absorption and acute metabolic effect after oral administration of these metabolites to preterm infants. We report on 10 low birthweight preterm infants who received an equivalent oral dose of 1 $\alpha, 25$-dihydroxycholecalciferol (Rocaltrol, Roche Products, Herts, United Kingdom) or $1 \alpha$-hydroxycholecalciferol (One-Alpha, Leo Laboratories, Bucks, UK).

\section{Patients and methods}

Two groups of five infants (two boys and three girls each) were studied. Group 1 , who had a median gestational age of 28 weeks (range 27-29 weeks) and birth weight of $1210 \mathrm{~g}$ (range 840-1360 g), received $0.1 \mu \mathrm{g} / \mathrm{kg}$ of One-Alpha at a median postnatal age of 4 weeks (range 3-5). Group 2, who had a median gestational age of 28 weeks (range 27-30 weeks) and birth weight of $1110 \mathrm{~g}$ (range $870-1200 \mathrm{~g}$ ), received $0.1 \mu \mathrm{g} / \mathrm{kg}$ of Rocaltrol at a median postnatal age of 4 weeks (range 3-5 weeks).

Both agents were prepared according to the manufacturer's protocol and given as a single morning oral dose. At the time of investigation the feeding regimens in both groups were identical; two infants in both were receiving expressed breast milk, two mixed feed, expressed breast milk, and standard formula feed, and one standard formula feed alone. No infant had clinical, biochemical, or radiological evidence of bone demineralisation or of hypocalcaemia.

Blood $(1.5 \mathrm{ml})$ was collected by venepuncture immediately predose and at six and 24 hours postdose. It was not considered ethically correct to take additional samples at other times. The first postdose sample time of six hours was chosen to approximate to the peak absorbed concentration time as based on available data from adults. ${ }^{3}$

Blood was separated within half an hour of collection and the plasma aliquoted and stored frozen at $-20^{\circ} \mathrm{C}$ till assayed. Plasma 25-hydroxycholecalciferol and 1 $\alpha, 25$-dihydroxycholecalciferol concentrations were assayed in duplicate by competitive protein binding after sephadex column separation by the method of Mallon et al. ${ }^{4}$ Individual patient samples were analysed within the same assay batch. The interassay coefficient of variation for 25 -hydroxycholecalciferol was $11 \%$ while for $1 \alpha, 25$-dihydroxycholecalciferol it was $12 \%$. Plasma calcium concentration was assayed by a manual 

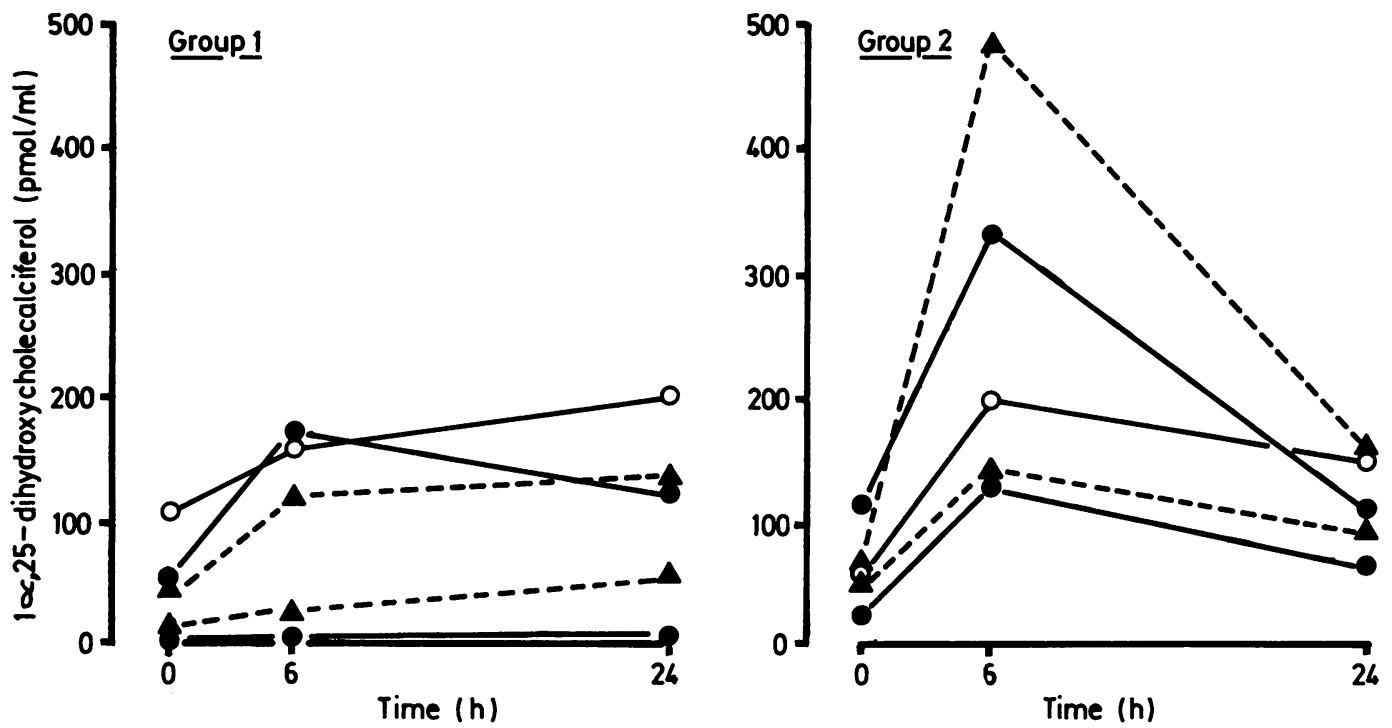

Figure Serial changes in plasma 1 $\alpha, 25$-dihydroxycholecalciferol concentrations after oral administration of $1 \alpha$-hydroxycholecalciferol (group 1) and $1 \alpha, 25$-dihydroxycholecalciferol (group 2). Feeding regimens at the time of study are as follows: - =xpressed breast milk; $\mathbf{\Delta}-\cdots \mathbf{\Delta}=$ mixed feed, expressed breast milk, and standard formula feed; $\mathrm{O}-\mathrm{O}=$ standard formula feed.

cresolphthalene compleximetric method with an intra-assay coefficient of variation of $2 \%$ and plasma inorganic phosphate concentration by a manual molybdate reduction method with an intra-assay coefficient of variation of $4 \%$. Statistical analysis of all biochemical variables was performed using the Mann-Witney U test. The study was approved by the hospital ethical committee, and informed consent was obtained.

\section{Results}

The median and range of the predose plasma $1 \alpha, 25$-dihydroxycholecalciferol concentration and

Table Incremental increase above predose concentrations of plasma 1 $\alpha, 25$-dihydroxycholecalciferol in two groups treated with vitamin $D$ metabolites. Values are median (range)

\begin{tabular}{|c|c|c|c|}
\hline & \multicolumn{3}{|c|}{ 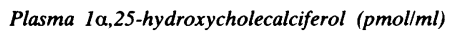 } \\
\hline & $\begin{array}{l}\text { Predose } \\
\text { concentrations }\end{array}$ & $\begin{array}{l}\text { Incremental } \\
\text { over predose } \\
\text { concentration }\end{array}$ & ease \\
\hline $\begin{array}{l}\text { Group } 1 \text { (One-Alpha) } \\
\text { Group } 2 \text { (Rocaltrol) }\end{array}$ & $\begin{array}{l}48(6 \cdot 5-108) \\
60(22-118)\end{array}$ & $\begin{array}{l}6 h \\
58(16-118) \\
134(79-421)\end{array}$ & $\begin{array}{l}24 h \\
65(8-95) \\
56(37-96)\end{array}$ \\
\hline
\end{tabular}

the median incremental increase above this basal concentration at six and 24 hours are shown in the Table. There was no significant difference between the predose concentrations of the two groups. In group 1 there was a sequential increase in plasma $1 \alpha, 25$-dihydroxycholecalciferol concentrations over the 24 hours, but this increase was not significant. In group 2, however, there was a significant increase at six hours $(\mathrm{p}<0.01)$, which returned towards the predose concentration at 24 hours (Figure).

Two infants in group 1 showed a net negative change in 25-hydroxycholecalciferol, whereas three infants in group 2 showed a similar change. At 24 hours all infants in group 1 and two in group 2 showed a net positive change. The changes were not significant, however, at either time.

There was no significant change in plasma calcium or inorganic phosphate concentration in either group at six or 24 hours.

\section{Discussion}

With the availability of more potent vitamin $\mathrm{D}$ metabolites or analogues, these agents have been increasingly prescribed both in the adult and in the infant for metabolic conditions associated with altered vitamin $\mathrm{D}$ metabolism. They have a number of therapeutic advantages over the parent com- 
pound cholecalciferol or ergocalciferol, in that they may not require in vivo hydroxylation within the liver and kidney for activation. This may be important in the preterm infant where a maturational delay in the renal enzyme $1 \alpha$ hydroxylase pathway has been implicated ${ }^{5}$ as one of the factors associated with the complex condition of rickets of prematurity. As the metabolites have an enhanced biological activity with a shorter half life compared with the parent compounds, the dose-response relation may be more easily controlled. The routine use of these agents in the prophylaxis or management of rickets of prematurity is, however, disputed. ${ }^{6}$

This study shows, for the first time, that $1 \alpha, 25$ dihydroxycholecalciferol (Rocaltrol) is adequately absorbed after oral administration and has a similar kinetic profile to that observed in adults. ${ }^{3}$ The precise timing of the peak concentration is uncertain as frequent blood sampling was not considered ethically justifiable in these infants. The gradual and persistent rise in plasma $1 \alpha, 25$-dihydroxycholecalciferol concentration after the oral administration of One-Alpha suggests that this analogue was also absorbed and subsequently underwent liver 25-hydroxylation. Whether 25-hydroxylation is necessary for maximal biological activity of One-
Alpha is uncertain (Leo Laboratories. Personal communication).

We thank the nursing staff of the Special Care Baby Unit at Queen Charlotte's Maternity Hospital for their help and Roche Products UK and Leo Laboratories UK for providing the active agents and for financial and technical support.

\section{References \\ ${ }^{1}$ Seino Y, Ishii T, Shimotsuji T, Ishida M, Yobuuchi H. Plasma active vitamin $D$ concentration in low birthweight infants with rickets and its response to vitamin D treatment. Arch Dis Child 1981;56:628-32. \\ 2 Barek Y, Milbaer B, Weilsman Y, Edelstein S, Spirev Z. Response of neonatal hypocalcaemia to 1-alpha hydroxyvitamin $\mathrm{D}_{3}$. Arch Dis Child 1979;54:642-3. \\ 3 Mason RS, Lissner D, Posen S, Norman AW. Blood concentra- tions of dihydroxylated vitamin $D$ metabolites after an oral dose. Br Med J 1980;280:449-50. \\ ${ }^{4}$ Mallon JP, Hamilton JG, Nauss-Karol C, et al. An improved competitive protein binding assay for 1,25-dihydroxyvitamin D. Arch Biochem Biophys 1980;201:277-85. \\ ${ }^{5}$ Kovar I, Mayne P, Wallis J. Neonatal rickets in one of identical twins. Arch Dis Child 1982;57:792-4. \\ ${ }^{6}$ Brooke OG, Lucas A. Metabolic bone disease in preterm infants. Arch Dis Child 1985;60:682-5.}

Correspondence to Dr I Z Kovar, Department of Child Health, Charing Cross Hospital, Fulham Palace Road, London W6.

Received 27 February 1986

\title{
Chlamydia trachomatis as a cause of neonatal conjunctivitis
}

\author{
W C BARRY, E L TEARE, A H C UTTLEY, S A WILSON, T J MCMANUS, K S LIM, \\ H GAMSU, AND J F PRICE
}

Public Health Laboratory, Dulwich Hospital, and Departments of Genito-Urinary Medicine and Child Health, King's College Hospital, London

SUMMARY Chlamydia trachomatis was identified in 37 of 73 consecutive neonates with purulent conjunctivitis, including four delivered by caesarean section with intact membranes. Most (28/37) presented in the first week. Infection was significantly associated with referral from the community. Genital C. trachomatis infection was present in 13 of 35 parents of affected infants.

Neonatal purulent eye discharge is common. British studies in $1977^{1}$ and $1982^{2}$ and a recent Danish report $^{3}$ have given rates of $8.4 \%, 12 \%$, and $25 \%$, respectively.

Bacterial pathogens were isolated in $33 \%$ of cases in the British study of $1982^{2}$ compared with $26 \cdot 6 \%$ in an American series ${ }^{4}$ in which Chlamydia trachomatis was isolated in a further $29.5 \%$ of cases as against $3 \%$ in the 1982 British study ${ }^{2}$ and none in the 1977 study. ${ }^{1}$

Because $C$. trachomatis has been increasingly identified in the Camberwell Health Authority as a cause of pelvic inflammatory disease and nonspecific and non-gonococcal genital infection ${ }^{5}$ we have studied the pattern and causes of neonatal conjunctivitis in our area. Parents of neonates with chlamydial or gonococcal conjunctivitis were investigated for genital infection.

\section{Patients and methods}

From August 1984 to January 1985 consecutive neonates with purulent conjunctivitis were recruited from the postnatal wards of King's College and Dulwich Hospitals, the neonatal intensive care unit, 